\title{
USO DO REJEITO DA DESSALINIZAÇÃO DE ÁGUA SALOBRA NO CULTIVO DA ALFACE (Lactuca sativa L.) EM SISTEMA HIDROPÔNICO NFT ${ }^{1}$
}

\author{
Use of the desalted wastewater for lettuce (Lactuca sativa $\mathbf{L}$.) \\ production in NFT hydroponic system
}

\author{
Rafaelly Suzanye da Silva Santos ${ }^{2}$, Nildo da Silva Dias ${ }^{3}$, \\ Osvaldo Nogueira de Sousa Neto ${ }^{3}$, Marcelo Tavares Gurgel ${ }^{3}$
}

\begin{abstract}
RESUMO
A dessalinização por osmose reversa tem sido bastante utilizada para o tratamento de água salobra, possibilitando a sua utilização para o consumo humano, especialmente em regiões semiáridas. Esse processo tem um fator limitante que é a produção de um rejeito de água com alta salinidade. Com o objetivo de avaliar os efeitos da utilização de água de rejeito da dessalinização no cultivo de alface cultivar Vera (Lactuca sativa L.) em sistema hidropônico NFT foi conduzido um experimento em casa de vegetação no departamento de ciências ambientais da UFERSA, em delineamento em blocos casualizados, com seis tratamentos e quatro repetições. Os níveis de salinidade da água entre os tratamentos foram obtidos com, ou sem a necessidade de diluição da água de rejeito da dessalinização acrescido da solução nutritiva com salinidade de $1 \mathrm{dS} \mathrm{m}{ }^{-1}$ (100\% de água potável de abastecimento - 1,4 $\mathrm{dS} \mathrm{m}^{-1} ; 85 \%$ abastecimento e $15 \%$ água de rejeito $-1,9 \mathrm{dS} \mathrm{m}^{-1} ; 75 \%$ água de rejeito $+25 \%$ água de abastecimento $-2,7 \mathrm{dS} \mathrm{m}^{-1} ; 50 \%$ água de rejeito e $50 \%$ água de abastecimento $-3,8$ $\mathrm{dS} \mathrm{m} \mathrm{m}^{-1} ; 25 \%$ água de rejeito e $75 \%$ água de abastecimento $-4,9 \mathrm{dS} \mathrm{m}^{-1}$ e água de rejeito coletada no dessalinizador $-5,5 \mathrm{dS} \mathrm{m} \mathrm{m}^{-1}$. Os parâmetros analisados foram área foliar, diâmetro do caule, número de folhas, peso de matéria fresca e o peso de matéria seca. Todas as variáveis estudadas foram influenciadas negativamente de forma linear pelo efeito da concentração de sais na água de irrigação, sendo que a área foliar e a matéria fresca da parte aérea são as que melhor representam a sensibilidade ao estresse salino na cultivar estudada, tendo a produção em termos de matéria fresca uma redução de $94,83 \%$, ao se elevar a CEa de 1,4 a $5,5 \mathrm{dS} \mathrm{m}^{-1}$.
\end{abstract}

Termos para indexação: Salinidade, impacto ambiental, reuso de água, água residuária.

\begin{abstract}
The desalination process by reverse osmosis was used for the treatment of brackish water, making possible the usage human consume in semiarid zones. This process has a limiting factor: it produces wastewater with high salinity. To evaluate the effect of the use of desalted water on lettuce (Lactuca sativa L.) production cv. Vera in a NFT hydroponics system an experiment was carried out in a greenhouse located at the Departament of Environmental Sciences of the Universidade Federal Rural do Semi-Árido, in a statistical test with completely randomized blocks with four repetitions and six treatments. The salinity level of the war between treatments was checked with and without dilution of the wastewater, adding the nutrient solution with salinity of $1 \mathrm{dS} \mathrm{m}^{-1}(100 \%$ public water supply $-1.4 \mathrm{dS} \mathrm{m}{ }^{-1} ; 85 \%$ water supply and $15 \%$ wastewater $-1.9 \mathrm{dS} \mathrm{m}^{-1} ; 75 \%$ wastewater $+25 \%$ water supply -2.7 $\mathrm{dS} \mathrm{m} \mathrm{m}^{-1} ; 50 \%$ wastewater e $50 \%$ water supply $-3.8 \mathrm{dS} \mathrm{m}^{-1} ; 25 \%$ wastewater and $75 \%$ water supply $-4.9 \mathrm{dS} \mathrm{m}^{-1}$ and wastewater gathered from desalter $-5.5 \mathrm{dS} \mathrm{m}^{-1}$. The number of leaves, diameter of the stem, fresh and matter biomass and leaf area were analyzed. All the analyzed variables were negatively influenced in a linear way by the effect of the concentration of salts in irrigation water. Biomass and leaf area are more sensitive to saline stress in the cultivar studied, and fresh matter production was reduced by $94.83 \%$, when CEa was increased from 1.4 to $5.5 \mathrm{dS} \mathrm{m}^{-1}$.
\end{abstract}

Index terms: Salinity, environmental impact, water reuse, wastewater.

(Recebido em 12 de janeiro de 2009 e aprovado em 14 de julho de 2009)

\section{INTRODUÇÃO}

A água é uma substância necessária a diversas atividades humanas, além de constituir componente fundamental da biosfera e ser solvente universal, sendo essencial à vida. Recurso de valor inestimável, ela tem utilidades múltiplas, como geração de energia elétrica, abastecimento doméstico e industrial, irrigação, navegação, recreação, turismo, aqüicultura, pesca e, ainda, assimilação e condução de despejos municipais, industriais e agropecuários (Lima et al., 1999).

No semiárido o abastecimento de água de muitas comunidades rurais é proveniente de águas subterrâneas e, na maior parte da região, essa água é salobra (Westcot, 1999) necessitando de tratamento para possibilitar a sua utilização para o consumo humano. A tecnologia amplamente utilizada tem sido a dessalinização por osmose reversa e, essa técnica tem um fator limitante que é a

${ }^{1}$ Parte da monografia de graduação do primeiro autor apresentada a UFERSA, para obtenção do título de Engenheiro agrônomo 'Universidade Federal Rural do Semi-Árido/UFERSA - Cx. P. 137 - 59625-900 - Mossoró, RN - raffaely@hotmail.com

${ }^{3}$ Universidade Federal Rural do Semi-Árido/UFERSA - Mossoró, RN 
produção de um rejeito de água com alta salinidade, o qual necessita ser utilizado de forma ambientalmente correta, possibilitando, sempre que possível, a produção de alimentos.

A dessalinização é um processo que converte água salobra em águas de boa qualidade, e vem sendo praticada há mais de 50 anos. A escassez de água de boa qualidade tem forçado o uso dessa prática em regiões áridas e semiáridas e nos países que fazem limite com mares ou lagos com águas salinas (Voutchkov, 2004).

Conforme Mickley (2004), a escolha da melhor opção para se dispor o rejeito da dessalinização deve atender, dentre outros fatores, às disponibilidades locais (terra, compatibilidade das águas receptoras e distância), às disponibilidades regionais (geologia, leis estaduais, geografia e clima), ao volume de concentrado, aos custos envolvidos, à opinião pública e à permissibilidade. Riley et al. (1997) consideraram o cultivo de plantas halófitas a melhor opção para dispor o rejeito da osmose reversa.

O aproveitamento do rejeito da dessalinização em solução nutritiva em cultivos hidropônicos de hortaliças é uma opção bastante promissora para dispor esse resíduo. Isso porque, de acordo com Soares (2007), apesar da alta concentração de sais no rejeito e do seu poder de contaminação, a tolerância das plantas à salinidade em sistemas hidropônicos pode ser maior em relação ao sistema convencional, pois é menor ou inexistente o efeito do potencial mátrico sobre o potencial total da água na hidroponia, o que pode reduzir a dificuldade de absorção de água e nutrientes pelas plantas com consequente aumento da salinidade limiar da cultura. Nesse sentido, em sistemas hidropônicos, espera-se que culturas, sobretudo de ciclo rápido, proporcionem o uso sustentável de águas salinas, naturais ou residuárias provenientes do processo de dessalinização.

Um grande desafio para a pesquisa seria contribuir para a solução da escassez de água para consumo humano e para o desenvolvimento de sistemas sustentáveis de produção com águas salinas para a produção de forragens e de culturas alimentares. A possibilidade de utilização de águas de qualidade marginal liberará água doce para beber e a identificação e obtenção de genótipos tolerantes a sais abrirão perspectivas para produção de alimentos vegetais para consumo direto da população e para alimentação animal, gerando proteínas para uso humano.

Levando-se em consideração estes aspectos, objetivou-se avaliar os efeitos da utilização de água de rejeito proveniente do processo de dessalinização por osmose reversa na cultura de alface (Lactuca sativa L.) em sistema hidropônico NFT.

\section{MATERIAL E MÉTODOS}

O trabalho foi conduzido no período de abril a junho de 2008, em casa de vegetação situada no Campus da Universidade Federal Rural do Semiárido - UFERSA, município de Mossoró-RN, a 5¹1' de latitude Sul e 37²0' de longitude Oeste, a uma altitude de $18 \mathrm{~m}$. O clima da região, segundo classificação de Köppen, é do tipo BSwh', ou seja, quente com estação chuvosa no verão, atrasando-se para o outono. A precipitação média anual é de $825 \mathrm{~mm}$, sendo março e abril os meses mais chuvosos. A temperatura média anual é de $27,4^{\circ} \mathrm{C}$, com média das máximas igual a $33,3^{\circ} \mathrm{C}$ e das mínimas $22,6^{\circ} \mathrm{C}$, a insolação média é de $236 \mathrm{~h}$ mensais e a umidade relativa média é de $68,9 \%$ (Carmo Filho \& Oliveira, 1989).

O delineamento estatístico adotado será o de blocos casualizados completos, com 6 tratamentos e 4 repetições, sendo cada bloco composto por seis níveis de condutividade elétrica da solução nutritiva para o cultivo da alface hidropônica, preparadas com água de abastecimento - $\mathrm{T}_{1}$ (testemunha), água de rejeito coletado no dessalinizador $-\mathrm{T}_{6}$ e da sua diluição com água de abastecimento à $85,75,50$ e $25 \%\left(\mathrm{~T}_{2}, \mathrm{~T}_{3}, \mathrm{~T}_{4}\right.$ e $\mathrm{T}_{5}$, respectivamente). Em todos, às água foram acrescidos os fertilizantes da solução nutritiva básica $(\mathrm{pH}=6,5$ e $\mathrm{CE}=1,0$ dS $\mathrm{m}^{-1}$ ), contendo a seguinte composição de macronutrientes $\left(\mathrm{g} \mathrm{L}^{-1}\right)$ : 0,5; 0,37; 0,14 e 27 de nitrato de cálcio, nitrato de potássio, MAP, sulfato de magnésio, respectivamente; e como fonte de micronutrientes foi adicionado 0,06 $\mathrm{g} \mathrm{L}^{-1}$ de Quelatec. Após a adição dos fertilizantes, a salinidade final da solução nutritiva para cada tratamento foram 1,4; 1,9, 2,7, 3,8, 4,9 e 5,5 dS m${ }^{-1}\left(\mathrm{~T}_{1}\right.$, $\mathrm{T}_{2}, \mathrm{~T}_{3}, \mathrm{~T}_{4}, \mathrm{~T}_{5}$ e $\mathrm{T}_{6}$, respectivamente). A água de rejeito do dessalinizador foi coletada na unidade de tratamento da comunidade Puxa Boi, no município de Mossoró-RN e a água doce foi proveniente do sistema de abastecimento do campus da UFERSA.

Cada parcela experimental foi constituída por uma canaleta de PVC, sobre traves de madeira a $1 \mathrm{~m}$ de altura, espaçadas de $0,20 \mathrm{~m}$ entre plantas e $0,30 \mathrm{~m}$ entre canaletas, tendo o orifício de alocação das mudas com 0,09 m de diâmetro. Cada tratamento foi representado por um sistema hidropônico NFT, composto basicamente por um tanque com capacidade de $150 \mathrm{~L}$ de solução nutritiva, um sistema de bombeamento, quatro canais de cultivo e um sistema de retorno ao tanque. A solução nutritiva era bombeada aos canais e escoa por gravidade, formando uma fina lâmina de solução que irrigava as raízes. O acionamento do sistema de bombeamento era controlado por timer, ligando e desligando o sistema, a cada 15 minutos durante o dia, 
permanecendo desligado durante a noite. Os canais de cultivos da bancada de produção tinham capacidade para 16 mudas, cada bancada possuía 5 canaletas (tratamentos) conectados a cinco diferentes reservatórios de abastecimento automático.

O plantio da alface (cv. Vera do grupo soltacrespa) foi realizado em 20 de abril de 2008 em bandejas de isopor com 128 células preenchidas com vermiculita. Após a germinação, as bandejas foram colocadas em um sistema DFT (Furlani et al., 1999), deixando-se escoar uma lâmina de solução nutritiva (aproximadamente de 4 a $5 \mathrm{~cm}$ ) suficiente para o desenvolvimento do sistema radicular das mudas, mantendo o substrato úmido e permitindo a absorção dos nutrientes. O transplante foi realizado aos 23 dias após o plantio, quando as plantas apresentaram de 5 a $6 \mathrm{~cm}$ de altura e cinco folhas (incluindo os cotilédones), com emissão da sexta. Para cada tratamento, diariamente foram feitas medições da condutividade elétrica e do $\mathrm{pH}$ da solução nutritiva com auxílio de um condutivímetro e um pHmetro, respectivamente.

A colheita foi realizada aos 25 dias após o transplantio (DAT) para a realização das análises de produção: diâmetro caulinar (DC), estimado com paquímetro digital; número de folhas (NF), determinado pela contagem de folhas verde maiores de $3,0 \mathrm{~cm}$ de comprimento, desprezando-se as amareladas e/ou secas, partindo-se das folhas basais até a última folha aberta; peso de matéria fresca (PMF), estimada por pesagem em balança digital de precisão; peso da matéria seca (PMS), determinada pelo peso seco em estufa com circulação forçada de ar a $70{ }^{\circ} \mathrm{C}$ até atingir peso constante, expresso em gramas e área foliar (AF), utilizando o integrador de área foliar, modelo LI-3100 da Licor.

Os resultados do experimento foram interpretados individualmente por meio da análise de variância com auxílio do software SISVAR. O fator quantitativo relativo aos níveis de salinidade foi analisado estatisticamente por meio de regressão polinomial (linear e quadrática), e aplicou-se o teste de média "F" a $5 \%$ de probabilidade.

\section{RESULTADOS E DISCUSSÃO}

Conforme a análise de variância dos dados (Tabela 1), todas as variáveis estudadas foram significativamente influenciadas pela salinidade da solução nutritiva $(\mathrm{p}>0,05)$.

O número de folhas alface decresceu linearmente com o incremento da salinidade da solução nutritiva com a adição de água de rejeito da dessalinização (Figura 1), com perdas relativa ao tratamento testemunha $\left(\mathrm{T}_{1}=1,4 \mathrm{dS} \mathrm{m}^{-1}\right)$ de 5,$40 ; 16,33 ; 25,11 ; 37,78$ e 44,26\% para $\mathrm{T}_{2}, \mathrm{~T}_{3}, \mathrm{~T}_{4}, \mathrm{~T}_{5}$ e $\mathrm{T}_{6}$, respectivamente, refletindo o efeito negativo da salinidade sobre a emissão de folhas. Vários autores reportam os efeitos da salinidade sobre o crescimento e desenvolvimento da alface (Shannon et al., 1983, Cramer \& Spurr, 1986, Tanji, 1990; Gervásio et al., 2000; Soares et al., 2007), não fazem referência ao efeito dos sais sobre a emissão de folhas, porém, todos se reportam à redução de fitomassa da parte aérea, levando-se a crer que tenha havido também redução do NF com o incremento da salinidade. Para Adams (1991), a tolerância das plantas à salinidade é influenciada por diversos fatores, incluindo o estágio de crescimento para o tempo de exposição, duração da exposição, condição ambiental, tipo de substrato e sistema de produção.

Comportamento semelhante para número de folhas foram obtidos por Soares et al. (2006) ao avaliar a utilização de águas salobras $(2,46,3,43,4,51,5,44,6,43,7,39,8,50 \mathrm{e}$ $9,20 \mathrm{dS} \mathrm{m}^{-1}$ ) no cultivo da alface (cultivar Verônica) em sistema hidropônico NFT como alternativa condizente ao semiárido brasileiro. Sob condições de deficiência hídrica induzida pelo efeito osmótico (seca fisiológica) é comum alterações morfológicas e anatômicas nas plantas, como medida de manter a absorção de água e reduzir a taxa de transpiração; dentre as mudanças morfológicas, destacase a redução do tamanho e do número de folhas, como constatado neste estudo (Taiz \& Zeiger, 2004).

Tabela 1 - Análise de variância para as características estudadas da alface hidropônica (cv. Vera) em função da salinidade da solução nutritiva com a adição da água de rejeito.

\begin{tabular}{lcccccc}
\hline \multirow{2}{*}{ Fator de variação } & \multirow{5}{c}{ Estatística F } \\
\cline { 3 - 7 } & GL & NF & AF & DC & PMF & PMS \\
\hline Salinidade & 5 & $11,704^{*}$ & $486061,6^{*}$ & $0,092^{*}$ & $1856,7^{*}$ & $787,34^{*}$ \\
Bloco & 3 & $3,840^{\text {n.s }}$ & $90844,2^{\text {n.s }}$ & $0,013^{\text {n.s }}$ & $462,7^{* *}$ & $164,65^{\text {n.s }}$ \\
\hline Média & & 7,29 & 545,57 & 0,72 & 29,84 & 19,55 \\
Coeficiente de variação (\%) & & 14,99 & 32,74 & 11,38 & 38,54 & 41,43 \\
\hline
\end{tabular}




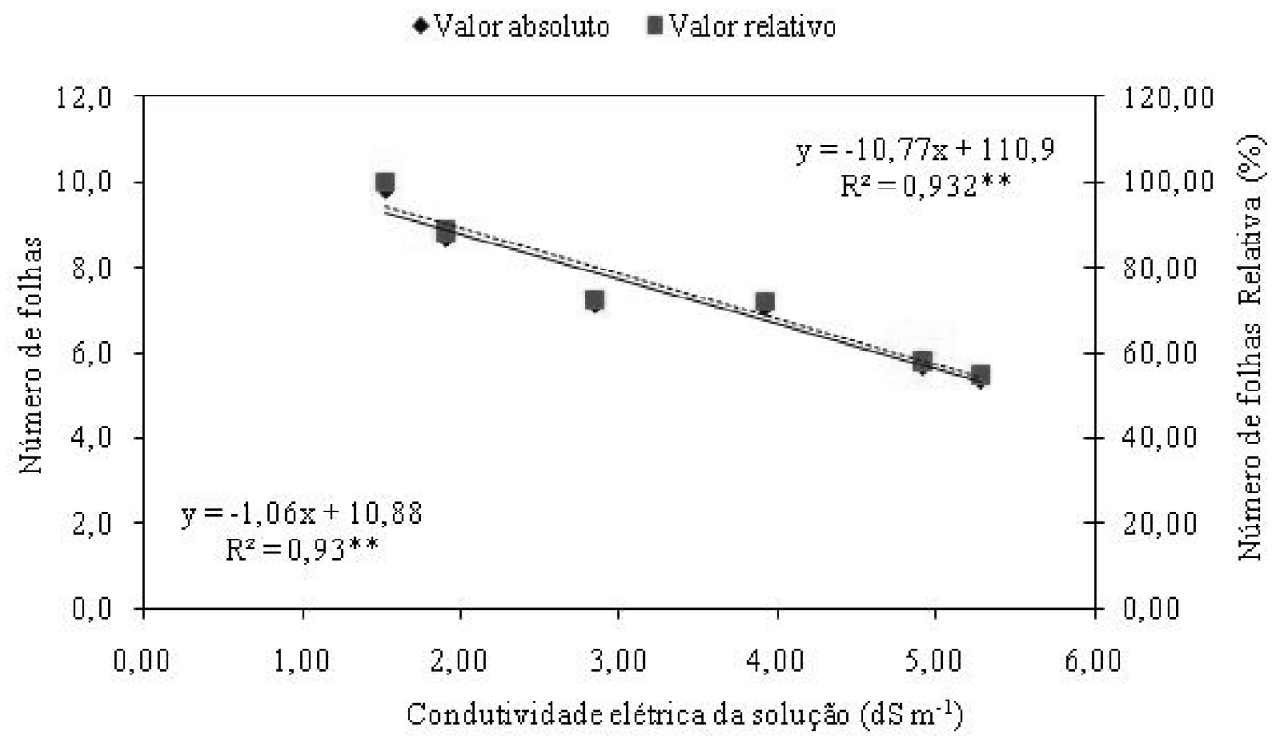

Figura 1 - Número de folhas absoluta e relativa da alface hidropônica (cv. Vera) em função da salinidade da solução nutritiva.

Assim, como verificado para o número de folhas, a área foliar também foi reduzida linearmente com o aumento da salinidade da solução nutritiva, sendo registrados perdas relativas ao tratamento testemunha de 10,$84 ; 39,26$; 52,$04 ; 75,90$ e $88,90 \%$ para $\mathrm{T}_{2}, \mathrm{~T}_{3}, \mathrm{~T}_{4}, \mathrm{~T}_{5}$ e $\mathrm{T}_{5}$, respectivamente (Figura 2). Comparando-se os decréscimos da AF com os do NF, constata-se que os desse último foram bastante inferiores. Com base nessa constatação, pode-se inferior que o parâmetro de tolerância AF é mais apropriado para se avaliar a tolerância da alface à salinidade, quando comparado ao parâmetro NF.

O decréscimo da área foliar provavelmente decorre da diminuição do volume de células e, segundo Mittova et al. (2002) e Sultana et al. (2002), as reduções de área foliar e de fotossíntese contribuem, de certo modo, para adaptação da cultura à salinidade. A redução da área foliar sob estresse hídrico pode ser um mecanismo de sobrevivência que permite a conservação de água, pela menor área transpiratória das plantas.

De acordo com análise de regressão, houve efeito linear da salinidade da solução nutritiva sob o DC, com decréscimos relativos à testemunha de 5,$02 ; 15,02 ; 24,10$; 35,16 e $41,18 \%$ para $\mathrm{T}_{2}, \mathrm{~T}_{3}, \mathrm{~T}_{4}, \mathrm{~T}_{5}$ e $\mathrm{T}_{6}$, respectivamente (Figura 3). Esses decréscimos foram semelhantes aos obtidos para o número folhas, mas ficando abaixo dos ocorridos para a área foliar, reforçando a maior sensibilidade desta última variável aos efeitos da solução nutritiva salina. Ao contrário dos resultados obtidos neste estudo para DC, Dias et al. (2005) ao avaliarem a produção de alface (cultivar Verônica) sob diferentes níveis de salinidade do solo (variando de 1 a $8 \mathrm{dS} \mathrm{m}^{-1}$, e testemunha com $0,3 \mathrm{dS} \mathrm{m}^{-1}$ ) verificaram comportamento quadrático, com ponto de máximo em $2,38 \mathrm{dS} \mathrm{m}^{-1}$. O efeito quadrático do meleiro à salinidade observado pelos autores deve-se, provavelmente, ao fato da utilização de fertilizantes para salinizar o solo, permitindo um pequeno incremento de fertilizantes no solo, acarretando em um consumo de luxo de nutrientes pela cultura e, consequente aumento no crescimento das plantas, compensando o efeito negativo da diminuição do potencial osmótico da solução.

Para as variáveis PMF e PMS, os decréscimos relativos (comparados a testemunha) em $\mathrm{T}_{2}, \mathrm{~T}_{3}, \mathrm{~T}_{4}, \mathrm{~T}_{5}$ e $\mathrm{T}_{6}$ foram de 11,$56 ; 42,99 ; 55,51 ; 80,95$ e $94,83 \%$ para PMF (Figura 4) e de 11,60; 43,18; 55,68; 81,21\% para PMS (Figura $5)$, respectivamente. Com base nos citados decréscimos, verifica-se que a tolerância da alface hidropônica (cv. Vera), frente ao aumento da salinidade da solução nutritiva com água de rejeito salino, foi semelhante para a matéria fresca e seca da parte aérea. Considerando a inexistência de sintomas que pudessem depreciar o preço de venda, a própria massa de matéria fresca foi assumida, nesse estudo, como produtividade comercial. Nesse sentido, a redução da PMF foi decorrente das reduções verificadas anteriormente no número de folhas, diâmetro do caule e área foliar, concordando com resultados obtidos por Dias et al. (2005). Helbel Junior et al. (2008), estudando os efeitos 
da salinidade sob a produção hidropônica da alface (cv. Vera) demonstraram que a solução nutritiva salina $(2,5 \mathrm{dS}$ $\mathrm{m}^{-1}$ ) reduziu significativamente a biomassa fresca e o diâmetro de caule das plantas, sendo esta, provavelmente, relacionada aos efeitos negativos ocasionados pela pressão osmótica.

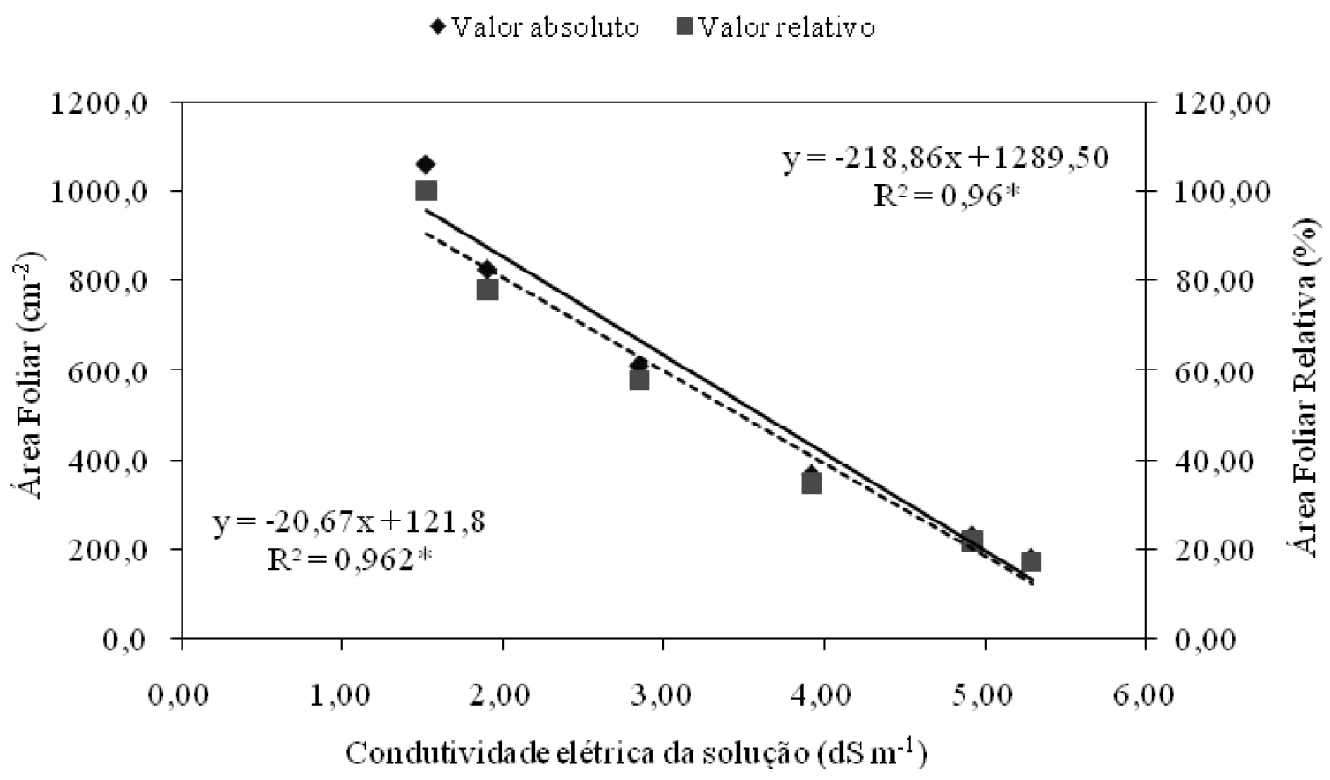

Figura 2 - Área foliar absoluta e relativa da alface hidropônica (cv. Vera) em função da salinidade da solução nutritiva.

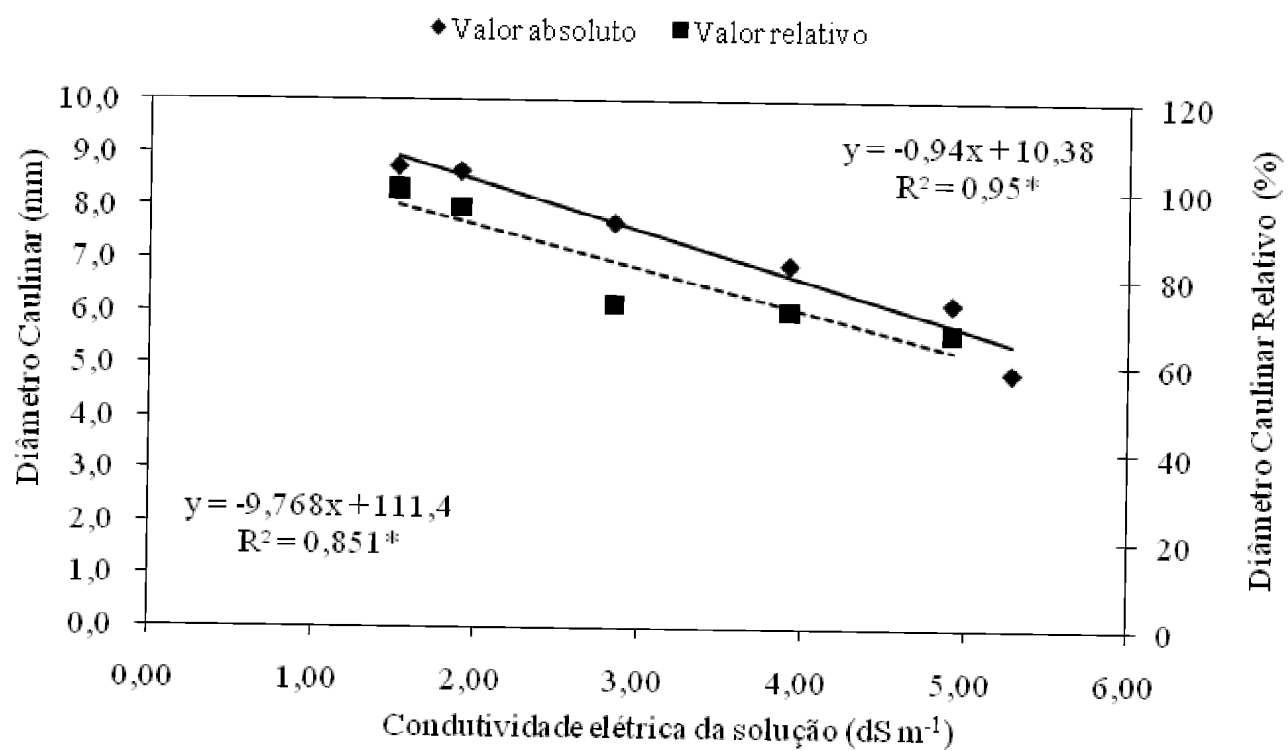

Figura 3 - Diâmetro do caule absoluto e relativo da alface hidropônica (cv. Vera) em função da salinidade da solução nutritiva. 


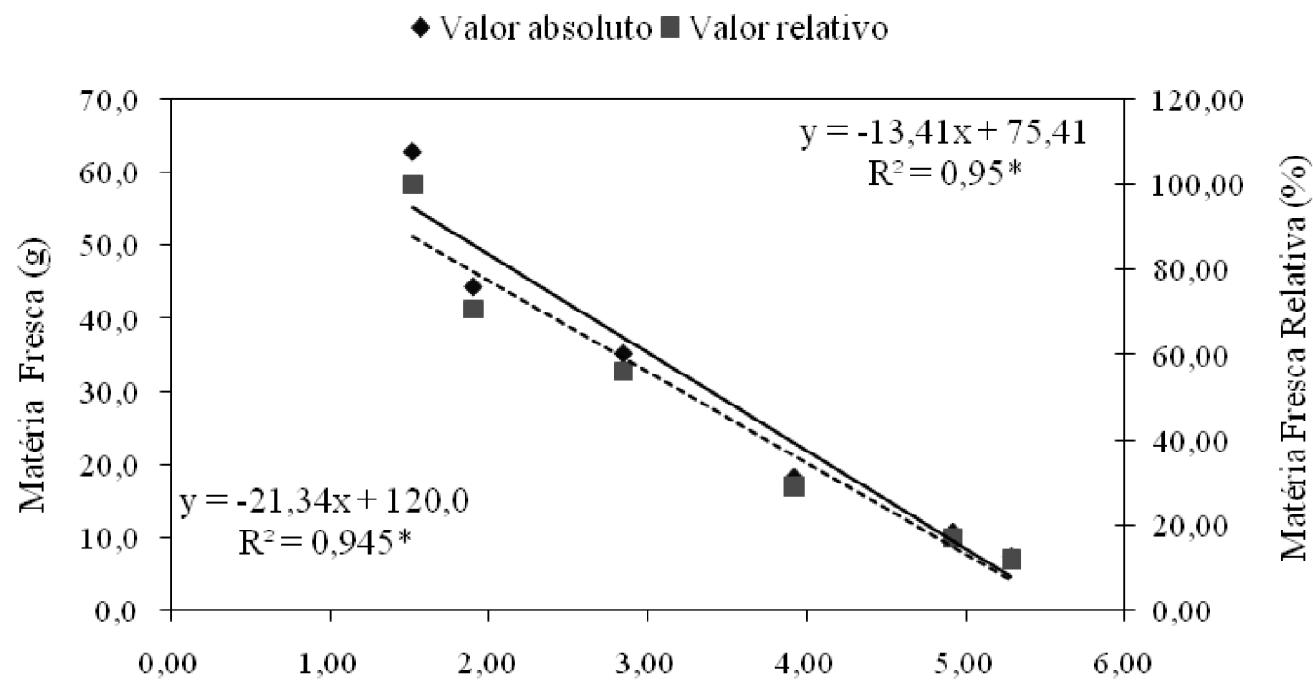

Condutividade elétrica da solução $\left(\mathrm{dS} \mathrm{m}^{-1}\right)$

Figura 4 - Peso de matéria fresca absoluta e relativa da alface hidropônica (cv. Vera) em função da salinidade da solução nutritiva.

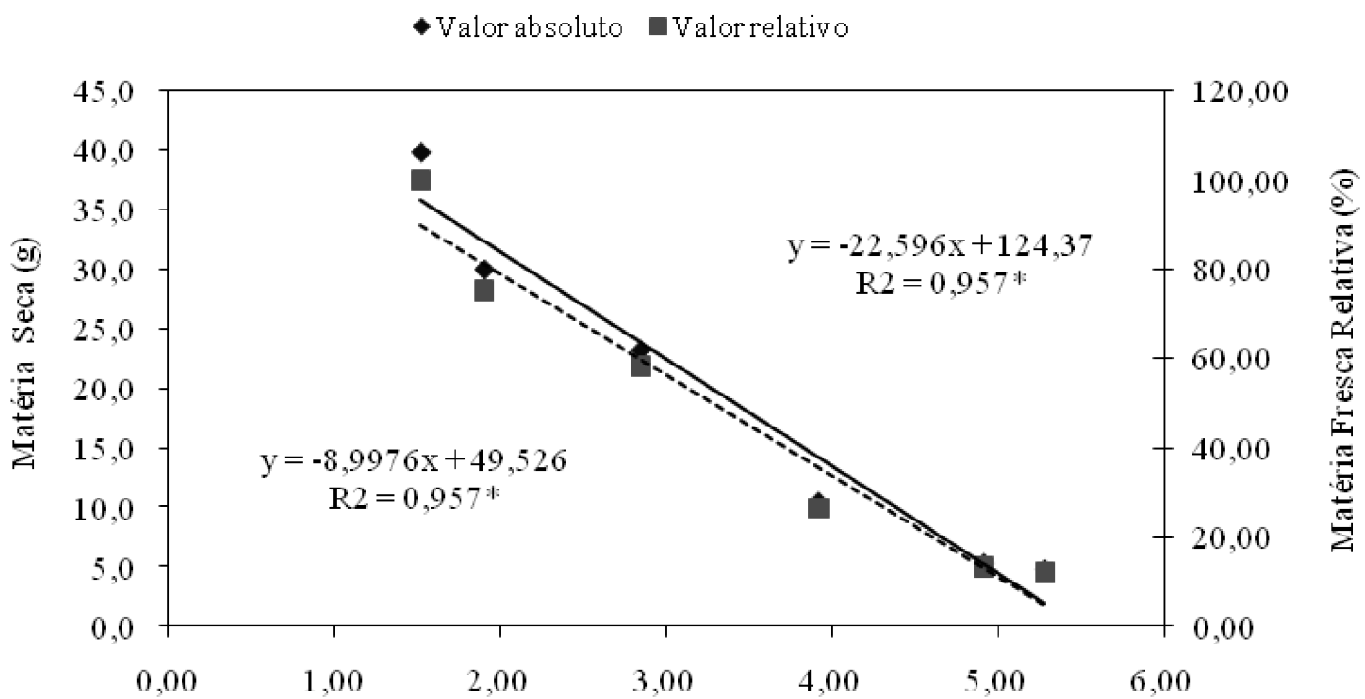

Condutividade elétrica da solução $\left(\mathrm{dS} \mathrm{m}^{-1}\right)$

Figura 5 - Peso de matéria seca absoluta e relativa da alface hidropônica (cv. Vera) em função da salinidade da solução nutritiva.

\section{CONCLUSÕES}

A utilização de rejeito da dessalinização no preparo da solução nutritiva reduziu linearmente o crescimento e a produção da alface hidropônica, sendo os efeitos mais severos sobre a variável área foliar.
A nutrição das plantas com água de rejeito inibiu o crescimento da alface hidropônica, com redução de 94,83\% do peso de matéria fresca em relação à nutrição com a solução nutritiva preparada com água de abastecimento, impossibilitando o cultivo comercial da cultura. 


\section{REFERÊNCIAS BIBLIOGRÁFICAS}

ADAMS, P. Effects of increasing the salinity of the nutrient solution with major nutrients or sodium chloride on the yield, quality and composition of tomatoes grown in Rockwool. Journal Horticulture Science, Cambridge, v.66, n.2, p.201-207, 1991.

CARMO FILHO, F. do; OLIVEIRA, O.F. de. Mossoró: um município do semi-árido nordestino: características climáticas e aspectos florísticos. Mossoró:

Mossoroense, 1989. 62p.

CRAMER, G.R.; SPURR, A.S. Responses of lettuce to salinity: I., effects of $\mathrm{NaCl}$ and $\mathrm{Na}_{2} \mathrm{SO}_{4}$ on growth. Journal of Plant Nutrition, New York, v.9, n.2, p.115-130, 1986.

DIAS, N.S.; DUARTE, S.N.; YOSHINAGA, R.T.; TELES FILHO, J.F. Produção de alface sob diferentes níveis de salinidade do solo. Revista Irriga, Botucatu, v.10, n.1, p.20-29, 2005.

FURLANI, P.R.; SILVEIRA, L.C.P.; BOLONHEZI, D.; FAQUIN, V. Cultivo hidropônico de plantas. Campinas: Instituto Agronômico, 1999. 52p. (Boletim técnico, 180).

GERVÁSIO, E.S.; CARVALHO, J.A.; SANTANA, M.J. Efeito da salinidade da água de irrigação na produção da alface americana. Revista Brasileira de Engenharia Agrícola e Ambiental, Campina Grande, v.4, n.1, p.125$128,2000$.

HELBEL JUNIOR, C.; REZENDE, R.; FREITAS, P. S. L. de; GONÇALVES A. C. A.; FRIZZONE, J. A. Influência da condutividade elétrica, concentração iônica e vazão de soluções nutritivas na produção de alface

hidropônica. Ciência e Agrotecnologia, Lavras, v.32, n.4, p.1142-1147, jul./ago.,2008.

LIMA, J.E.F.W.; FERREIRA, R.S.A.; CRISTOFIDIS, D. O Estado das água no Brasil: uso da irrigação no Brasil. São Paulo: Agencia nacional de Energia Elétrica, 1999. CD-ROM.

MICKLEY, M.C. Membrane concentrate disposal: practices and regulation. Denver: U.S. Department of the Interior, 2004. (Desalination and water purification research and development program report, 69). Disponível em: <http://www.usbr.gov/pmts/water/media/, ipdfs/report069.pdfi>. Acesso em: 20 fev. 2008.
MITTOVA, V.; TAL, M.; VOLOKITA, M.; GUY, M. Salt stress induces up-regulation of an efficient chloroplast antioxidant system in the salt-tolerant wild tomato species but not in the cultivated species. Physiologia Plantarum, Copenhagen, v.115, n.3, p.393-400, 2002.

RILEY, J.J.; FITZSIMMONS, K.M.; GLENN, E.P. Halophyte irrigation: an overlooked strategy for management of membrane fraction concentrate. Desalination, Amsterdam, v.110, n.3, p.197-211, 1997.

SHANNON, M.C.; MCCREIGTH, J.D.; DRAPER, J.H. Screening test for salt tolerance in lettuce. Journal of the American Society for Horticultural Science, Mount Vermon, v.108, n.2, p.225-230, 1983.

SOARES, T.M. Utilização de águas salobras no cultivo da alface em sistema hidropônico NFT como alternativa agrícola condizente ao semi-árido brasileiro. 2007. 268p. Tese (Doutorado em Agronomia)-Escola Superior de Agricultura "Luiz de Queiroz", Universidade de São Paulo, Piracicaba, 2007.

SOARES, T.M.; SILVA, E.F.F.; DUARTE, S.N.; MÉLO, R.F.; JORGE, C.A.; BONFIM-SILVA, E.M. Produção de alface utilizando águas salinas em sistema hidropônico. Irriga, Botucatu, v.12, n.2, p.235-248, 2007.

SOARES, T.M.; SILVA, I.J.O. da; DUARTE, S.N.; SILVA, Ê.F. de F. e. Destinação de águas residuárias provenientes do processo de dessalinização por osmose reversa. Revista Brasileira de Engenharia Agrícola e Ambiental, Campina Grande, v.10, n.3, p.730-737, 2006.

SULTANA, N.; KEDA, T.; KASHEM, M.A. Effect of seawater on photosynthesis and dry matter accumulation in developing rice grains. Photosynthetica, Prague, v.40, n.1, p.115-119, 2002.

TAIZ, L.; ZEIGER, E. Plant physiology. 3.ed. Sunderland: Sinauer Associates, 2004. 690p.

TANJI, K.K. Agricultural salinity assessment and management. New York: ASCE, 1990. 610p. (ASCE Manuals and Reports of Engineering Practices, 71).

VOUTCHKOV, N. The ocean: a new resource for drinking water. [S.1.], Public Works, 2004. 30p. 